\title{
Study Structure and Properties of Nanocomposite Material Based on Unsaturated Polyester with Clay Modified by Poly(ethylene oxide)
}

\author{
Tran Duy Thanh, ${ }^{1}$ Nguyen Dang Mao, ${ }^{1}$ Nguyen Thi Kim Ngan, ${ }^{1}$ Ha Thuc Chi Nhan, \\ Ha Thuc Huy, ${ }^{2}$ and Anne-Cecile Grillet ${ }^{3}$ \\ ${ }^{1}$ Polymer and Composites Research Group, Department of Material Science, University of Science, Ho Chi Minh City, Vietnam \\ ${ }^{2}$ Department of Physical Chemistry, University of Science, 227-Nguyen Van Cu Road, Ho Chi Minh City, Vietnam \\ ${ }^{3}$ Laboratoire des Matériaux Organiques à Propriétés Spécifiques, UMR 5041 CNRS-Université de Savoie, \\ Savoie Technolac, 73276 Le Bourget du Lac, France
}

Correspondence should be addressed to Anne-Cecile Grillet, anne-cecile.grillet@univ-savoie.fr

Received 5 December 2011; Accepted 26 December 2011

Academic Editor: Sevan P. Davtyan

Copyright (C) 2012 Tran Duy Thanh et al. This is an open access article distributed under the Creative Commons Attribution License, which permits unrestricted use, distribution, and reproduction in any medium, provided the original work is properly cited.

In recent years, polymer clay nanocomposites have been attracting considerable interests in polymers science because of their advantages. There are many scientists who researched about this kind of material and demonstrated that when polymer matrix was added to little weight of clay, properties were enhanced considerably. Because clay is a hydrophilic substance so it is difficult to use as filler in polymer matrix having hydrophobic nature, so clay needs to be modified to become compatible with polymer. In this study, poly(ethylene oxide) was used as a new modifier for clay to replace some traditional ionic surfactants such as primary, secondary, tertiary, and quaternary alkyl ammonium or alkylphosphonium cations having the following disadvantages: disintegrate at high temperature, catalyze polymer degradation, and make nanoproducts colorific, and so forth. In order to evaluate modifying effect of poly(ethylene oxide), modified clay products were characterize $\mathrm{d}$ by X-ray spectrum. Then organoclay was used to prepare nanocomposite based on unsaturated polyester. Morphology and properties of nanocomposites were measure d by Xray diffraction, transmission electron microscopy, tensile strength, and thermal stability. The results showed that clay galleries changed to intercalated state in the nanocomposites. Properties of nanocomposites were improved a lot when the loading of the organoclay was used at $1 \mathrm{phr}$.

\section{Introduction}

Polymer clay nanocomposites (PCNs) are one of the ways for making new materials that frequently exhibit remarkable improvements of material properties to replace traditional products in many applications $[1,2]$. The PCNs based on unsaturated polyester and nanoclay (MMT) also have been widely researched by scientists in the world for many years. The results showed that when clay dispersed in the form of exfoliated state or intercalated state, properties of PCNs such as tensile strength, flexural strength, gas permeability and biodegradability were improved significantly [3-6]. In recent time, the trend using nonion modifiers demonstrated that they had many promising applications in nanocomposite material field $[5,7-12]$. So in this study we have tried using poly(ethylene oxide) (PEO) as a new modifier to replace some traditional ionic surfactants such as primary, secondary, tertiary, and quaternary alkyl ammonium or alkylphosphonium cations having, disadvantages: disintegrate at high temperature, catalyze polymer degradation, and make nanoproducts colorific [13]. Then nanocomposite materials based on Unsaturated Polyester resin (UP) with PEO modified clay were prepared by solution method. The morphology and properties of PCNs were tested through XRD, TEM, mechanical strength, and thermal behavior. 


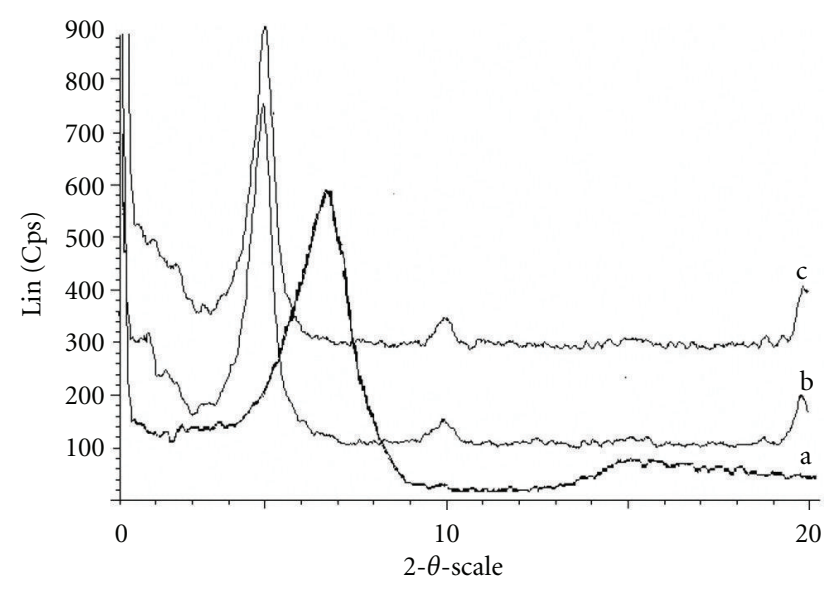

FIGURE 1: XRD diffraction of $\mathrm{N}_{757}$ : (a) virgin $\mathrm{N}_{757} ; \mathrm{N}_{757}$ modified by $\mathrm{PEO}$ at ratios (b) $10 / 3$ and (c) $10 / 5$.

\section{Experimental Methods}

2.1. Materials. Poly(ethylene oxide) (PEO), $M_{n}=100.000$, used as a non-ion modifier, was provided by Alrich Co., Germany. Commercial unmodified clay under trade name of $\mathrm{N}_{757}$ was from Sud-Chemie Co., Germany. Unsaturated polyester (UP) SHCP 268 BQT having 32\% wt of styrene is from Highpolymer Chemical Products Co., Singapore. Wax 8 was supplied by Meguiar Company, USA. And Ethyl Methyl Ketone Peroxide (MEKP) was obtained from AkzoNobel Company.

\subsection{Experiment}

2.2.1. Modify MMT by Melting Method (Isothermal Annealing). Clay and PEO were used according to two ratios $10: 3$ and 10:5. The suitable weights were mixed and grinded finely in one hour to enhance interface area between PEO and clay. Then mixture was annealed at $90^{\circ} \mathrm{C}$ in 8 hour. During this time, PEO was melted and adsorbed into interlayer structure of clay. The receipted organoclay was stored under vacuum condition in a desiccator.

2.2.2. Modify Clay by Solution Method. Clay and PEO were dissolved into solvent system water: ethanol and the weight ratio of clay and solvent were about 30:1. Solution was stirred at $40^{\circ} \mathrm{C}$ during 4 hours. After that it was centrifuged and wasted by ethanol. Receipted modified clay was dried at $40^{\circ} \mathrm{C}$ and then stored under vacuum condition in desiccator.

2.2.3. Preparation of Nanocomposite Materials. Nancomposite materials were prepared based on unsaturated polyester and organoclay at three clay contents 1,3 , and 5 phr (phr: parts per hundred resins). Firstly, UP and organoclay were mixed together in a closed container at $80^{\circ} \mathrm{C}$ in 6 hour. Then mixture was cooled down to room temperature. 1 phr of MEKP was added into mixture and stirred in one minute. After that solution was poured into the mould placed in a stove at $60^{\circ} \mathrm{C}$ in 24 hour. Continuously, achieved

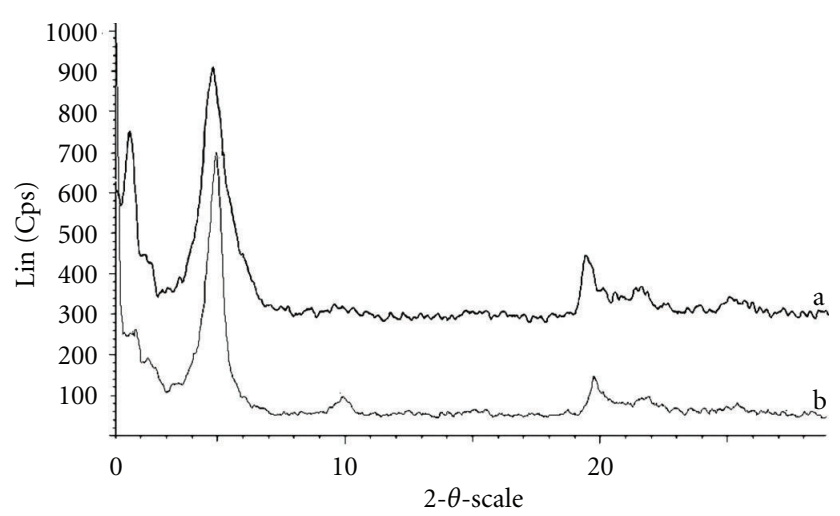

FIgure 2: XRD diffraction of $\mathrm{N}_{757}$ modified by $\mathrm{PEO}$ at ratio $10 / 3$ according two methods: (a) solution method and (b) melting method.

nanocomposites were taken out and gone through the postcure process at room temperature in 24 hours to define shape of the samples. Finally, PCNs were processed into suitable size to test structure and properties.

\section{Results and Discussion}

\subsection{Structure of $N_{757}$ Modified by PEO}

3.1.1. Effect of PEO Contents on Structure of $N_{757}$. Structure of clays was characterized from X-ray diffractograms of a D8 Advance (Bruker Germany) with Ni-filtered $\mathrm{CuK} \alpha$ radiation of wavelength $1.54 \AA$ at $40 \mathrm{kV}$ and $40 \mathrm{~mA}$. Figure 1 shows the XRD pattern of unmodified and modified clay. The original MMT had basal spacing of $12.4 \AA$. After it was modified by $\mathrm{PEO}$, the peak corresponding to the basal spacing of MMT disappeared and new peaks appeared with d-spacing of 17.9 and $18.2 \AA$ in samples having clay: PEO ratios $10: 3$ and $10: 5$, respectively. However, d-spacing of MMT was not enhanced considerably as the clay: PEO ratios were increased from 10:3 to $10: 5$. It is concluded that PEO dispersed into structure of MMT and adsorption gained the saturated value at ratio $10: 3$. That was completely suitable to results researched by author Shen et al. [9].

3.1.2. Effect of Modifying Method on Structure of Clay. Figures 2(a) and 2(b) show the XRD patterns of modified clay synthesized by solution and melting method, respectively.

At the modified clay: PEO ratio $10: 3$, results display that the melting method was better than solution method. For example, the d-spacing of organoclay modified by isothermal annealing method had stronger intensity and appeared at dspacing higher than sample from solution method. Besides, melting method (isothermal annealing) was more simple, economic, and easy to process than solution method. So it was a good method to be chosen for modifying MMT by PEO. 


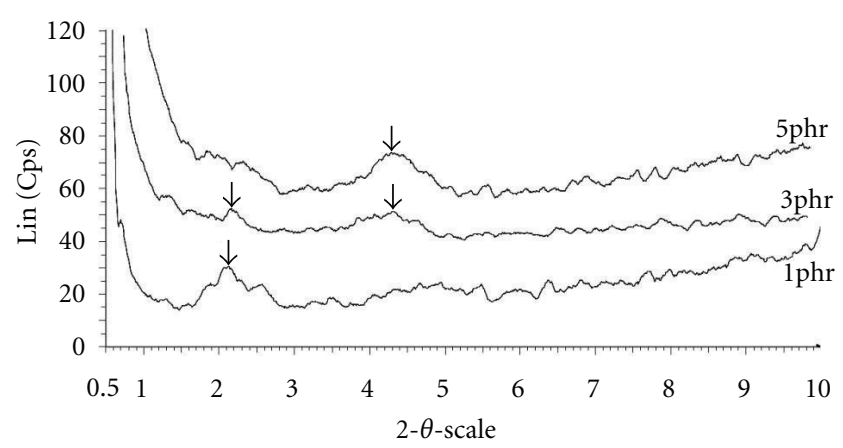

FIGURE 3: XRD diffraction of nanocomposite samples with three various contents of organoclay (a) $1 \mathrm{phr}$, (b) $3 \mathrm{phr}$, and (c) $5 \mathrm{phr}$.

\subsection{Structure and Properties of Nanocomposites Based on UP and Organoclay Modified by PEO}

3.2.1. Characterization Structure of Nanocomposite Materials. Figure 3 shows that when clay concentration reached $1 \mathrm{phr}$, peaks $\mathrm{d}_{001}$ moved to $41.39 \AA$. The original structure of MMT has been broken down to intercalated state in polymer matrix, suggesting that a great amount of polymer has dispersed into the interlayer space and expanded the MMT structure widely. At higher filler content such as 3 and $5 \mathrm{phr}$, only a part of clay was extended to intercalated structure and the remains still kept under original structure of organoclay. Specific peaks of clay contents 3 and $5 \mathrm{phr}$ low intensity appeared at d-spacing $=18.7 \AA$ and $18.4 \AA$, respectively. That means crystal structure of MMT was not destroyed and the nanocomposites exhibited partially intercalated structures.

Even though XRD spectrum was a useful technique to investigate interlayer $\mathrm{d}$-spacing of clay, it was not enough to characterize internal structure of nanocomposites. Therefore, TEM images were essential to observe a direct evidence of what structure exists in the PCNs as shown in Figure 4 for $1 \mathrm{phr}$ (a), $3 \mathrm{phr}$ (b), and $5 \mathrm{phr}$ (c). From Figure 4(a), the MMT layers were dispersed well into UP to gain intercalated structure at $1 \mathrm{phr}$ clay loading. These results could possibly due to poly(ethylene oxide) existing in structure was as a bridge to connect between the UP chains and MMT layers to help UP enter into and expand widely structure of clay to make intercalated state. Meanwhile, the agglomerates were found in the samples containing 3 and $5 \mathrm{phr}$ clay and quantity of the agglomerates was highest at the samples containing $5 \mathrm{phr}$ clay (Figures $4(\mathrm{a})$ and 4(b)). That means that although MMT was modified to become more compatible with polymer matrix, hydrophilic nature did not change remarkably. When clay content increased, the dispersion of clay was limited and kept the agglomerates in polymer matrix.

\subsubsection{Characterization Mechanical Properties of Nanocom-} posite Materials. All samples were prepared according to standard ASTM D638 and tested by a Cotech Machine (Taiwan). Generally, tensile strength of PCNs tended to
TABLE 1: Thermal data of UP/clay nanocomposites according to various clay contents.

\begin{tabular}{lcc}
\hline Clay content $(\mathrm{phr})$ & $\begin{array}{c}\text { Onset deg. } \\
\text { temperature }\left({ }^{\circ} \mathrm{C}\right)\end{array}$ & $\begin{array}{c}\text { Max. deg. } \\
\text { temperature }\left({ }^{\circ} \mathrm{C}\right)\end{array}$ \\
\hline 0 & 373 & 412 \\
1 & 374 & 419 \\
3 & 358 & 424 \\
5 & 370 & 423 \\
\hline
\end{tabular}

increase with an increasing clay loading. Tensile modulus of PCNs had the best values with MMT content up to $1 \mathrm{phr}$ as shown in Figure 5. Tensile stress also increased according to contents of modified MMT $1 \mathrm{phr}, 3 \mathrm{phr}$ and then decreased at $5 \mathrm{phr}$. These results were due to modified MMT compatible with UP dispersed very well in PCNs to create intercalated structure at clay content $1 \mathrm{phr}$, so that it significantly improved mechanical properties of nanomaterials. At high loading levels, such as 3 and $5 \mathrm{phr}$ of clay, polymer-clay interactions were lower, so MMT could not disperse well into polymer matrix. That resulted in agglomeration of the clay particles. The cross-link density could also be decreased at high clay contents, leading to tensile strength of PCNs being not improved, especially at loading of MMT $5 \mathrm{phr}$.

Figure 6 shows that the flexural strength also depended on the nanoclay content. The flexural strength increased from the unsaturated polyester to $1 \mathrm{phr}$ MMT and after that it decreased. The flexural strength behavior confirmed that clay dispersed well at $1 \mathrm{phr}$. At 3 and $5 \mathrm{phr}$ of clay contents, the creation of agglomerates caused intercalation poor, so it made a decrease of strength.

\subsubsection{Characterization Thermal Property of Nanocomposite} Materials. The thermal stability of the samples was evaluated at the heating rate of $20^{\circ} \mathrm{C} / \mathrm{min}$ from room temperature to $800^{\circ} \mathrm{C}$ by using TA Instruments (USA) with TGA-Q500. The thermal property of $0,1,3$, and $5 \mathrm{phr}$ organoclayloaded UP is shown in Table 1. UP has the onset degradation temperature at $373^{\circ} \mathrm{C}$ and gained maximum degradation temperature at $411^{\circ} \mathrm{C}$. All nanocomposites indicated that there was also a single-step thermal degradation like UP. The Thermogravimetric analysis demonstrated that the filling of MMT in the UP affected thermal stability. The presence of organoclay made PCNs have relatively higher thermal stability than UP. These results may be clay existing in structure of nanocomposites acts as a heat barrier. The improvement of thermal property was mainly effected by the degree of dispersion of clay in polymer matrix. From the table, it can be concluded that the thermal property of UP/clay nanocomposites was slightly enhanced as the clay content increased.

\section{Conclusion}

Addition of organoclay in relatively low weight to unsaturated polyester resin resulted in intercalated nanocomposites. From XRD patterns, the d-spacing of the organoclay 


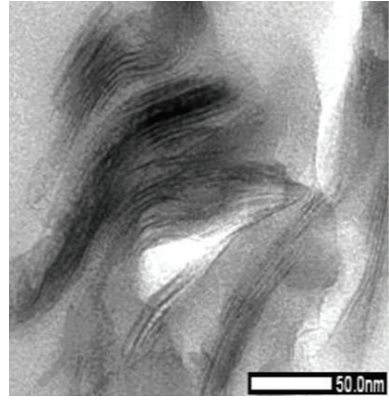

(a)

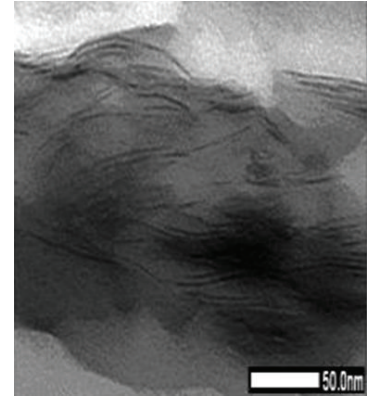

(b)

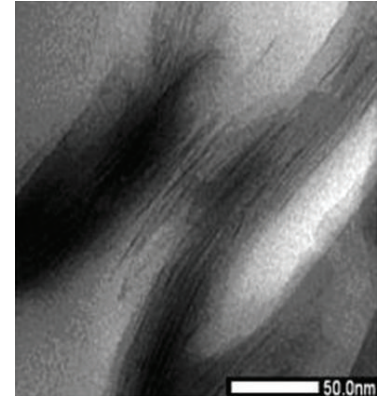

(c)

FIGURE 4: TEM of nanocomposite samples with three various contents of organoclay (a) 1 phr, (b) 3 phr, and (c) 5 phr.

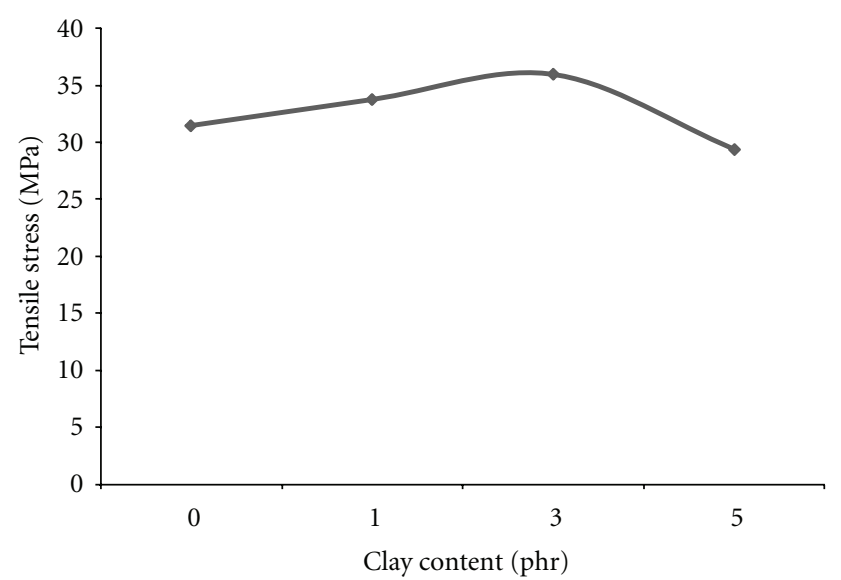

(a)

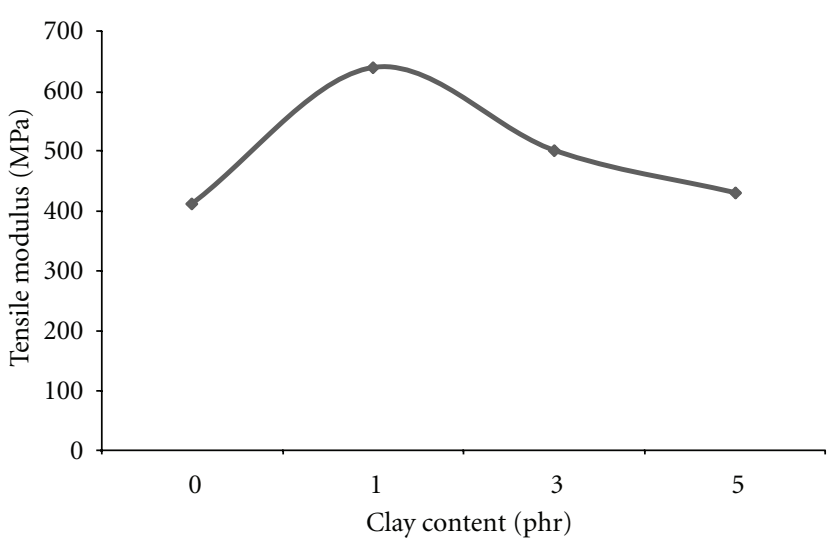

(b)

FIGURE 5: Tensile strength of nanocomposite materials according to various clay contents.

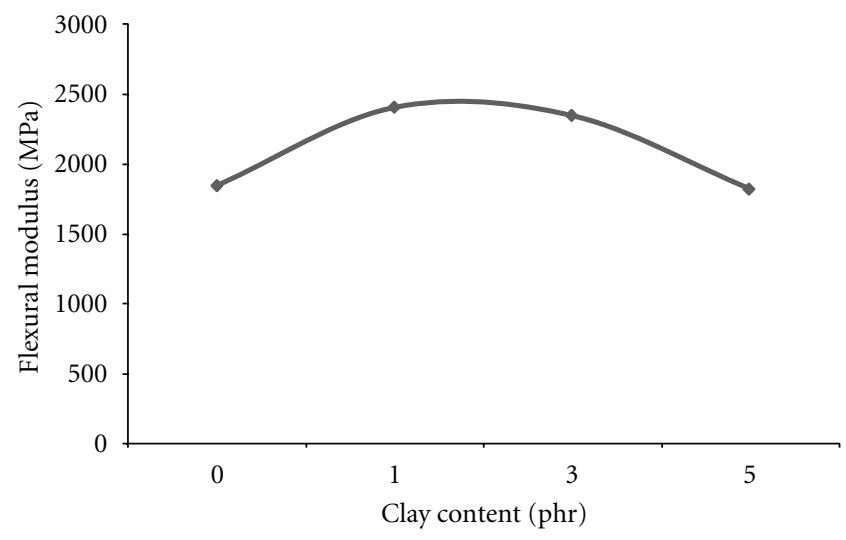

(a)

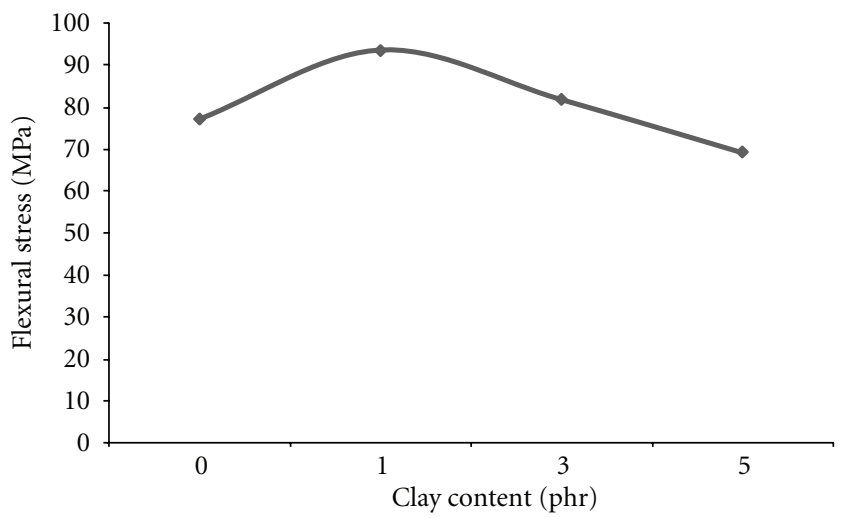

(b)

FIGURE 6: Flexural strength of nanocomposite materials according to various clay contents.

expanded from $17.94 \AA$ to $41.30 \AA$ to make intercalated structure in PCNs at $1 \mathrm{phr}$ of modified MMT loading. TEM images of the PCNs showed presence of organoclay with nanosized dispersion in the polymer matrix. MMT dispersed well in matrix polymer to form exfoliated state or intercalated state. Degradation temperature values of the PCNs were enhanced when clay contents increased from 1 to 5 phr. Besides, mechanical properties of PCNs were also improved better than virgin unsaturated polyester. Mechanical properties showed improvement noticeably and express the best results at loading of modified MMT 1 phr. Though results were achieved from studying properties by using testing techniques, we have succeeded to prepare nanomaterials based on UP resin with PEO-modified MMT. 
Initial results prove that MMT could be modified by PEO and they also opened up a new trend to modify clay to apply for preparing polymer nanomaterials in future.

\section{Acknowledgments}

The study is supported by a grant from the Department of Material Science, Ho Chi Minh University of Science. The authors thank all participants for their enthusiasm and cooperation in the study.

\section{References}

[1] S. S. Ray and M. Okamoto, "Polymer/layered silicate nanocomposites: a review from preparation and processing," Progress in Polymer Science, vol. 28, no. 11, pp. 1539-1641, 2003.

[2] B. Kblera and M. Jaboyedoffa, "Illite crystallinity," Earth and Planetary Sciences, vol. 331, pp. 75-89, 2000.

[3] J. H. Chang, T. G. Jang, K. J. Ihn, W. K. Lee, and G. S. Sur, "Poly(vinyl alcohol) nanocomposites with different clays: pristine clays and organoclays," Journal of Applied Polymer Science, vol. 90, no. 12, pp. 3208-3214, 2003.

[4] K. A. Carrado, P. Thiyagarajan, and D. L. Elder, "Polyvinyl alcohol-clay complexes formed by direct synthesis," Clays and Clay Minerals, vol. 44, no. 4, pp. 506-514, 1996.

[5] Y. H. Yua, C. Y. Lin, J. M. Yeh, and W. H. Lin, "Preparation and properties of poly(vinyl alcohol)-clay nanocomposite materials," Polymer, vol. 44, no. 12, pp. 3553-3560, 2003.

[6] E. Chiellini, A. Corti, S. D’Antone, and R. Solaro, "Biodegradation of poly(vinyl alcohol) based materials," Progress in Polymer Science, vol. 28, no. 6, pp. 963-1014, 2003.

[7] C. N. H. Thuc, A. C. Grillet, L. Reinert, F. Ohashi, H. H. Thuc, and L. Duclaux, "Separation and purification of montmorillonite and polyethylene oxide modified montmorillonite from Vietnamese bentonites," Applied Clay Science, vol. 49, no. 3, pp. 229-238, 2010.

[8] T. N. Abraham, D. Ratna, S. Siengchin, and J. Karger-Kocsis, "Structure and properties of polyethylene oxide-organo clay nanocomposite prepared via melt mixing," Polymer Engineering and Science, vol. 49, no. 2, pp. 379-390, 2009.

[9] Z. Shen, G. P. Simon, and Y. B. Cheng, "Saturation ratio of poly(ethylene oxide) to silicate in melt intercalated nanocomposites," European Polymer Journal, vol. 39, no. 9, pp. 19171924, 2003.

[10] Z. Shen, G. P. Simon, and Y. B. Cheng, "Effects of molecular weight and clay organo-ions on the melt intercalation of poly(ethylene oxide) into layered silicates," Polymer Engineering and Science, vol. 42, no. 12, pp. 2369-2382, 2002.

[11] K. E. Strawhecker and E. Manias, "Structure and properties of poly(vinyl alcohol)/ $\mathrm{Na}^{+}$montmorillonite nanocomposites," Chemistry of Materials, vol. 12, no. 10, pp. 2943-2949, 2000.

[12] S. G. de Bussetti and E. A. Ferreiro, "Adsorption of poly(vinyl alcohol) on montmorillonite," Clays and Clay Minerals, vol. 52, no. 3, pp. 334-340, 2004.

[13] D. Dharaiya and S. C. Jana, "Thermal decomposition of alkyl ammonium ions and its effects on surface polarity of organically treated nanoclay," Polymer, vol. 46, no. 23, pp. 10139-10147, 2005. 

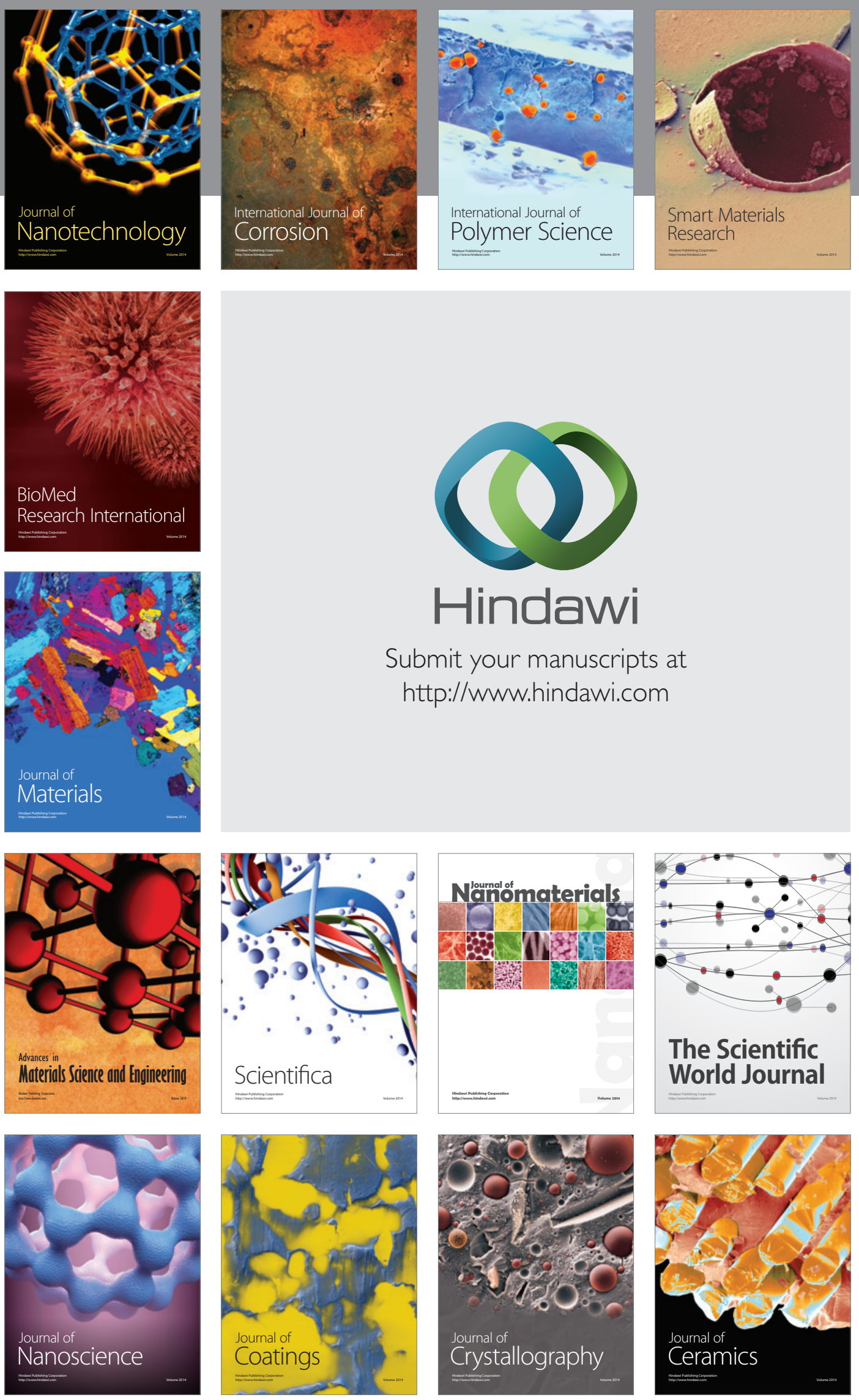

The Scientific World Journal

Submit your manuscripts at

http://www.hindawi.com

\section{World Journal}

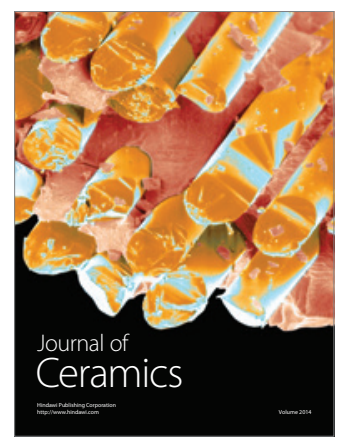

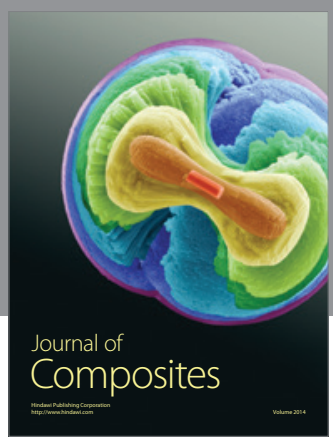
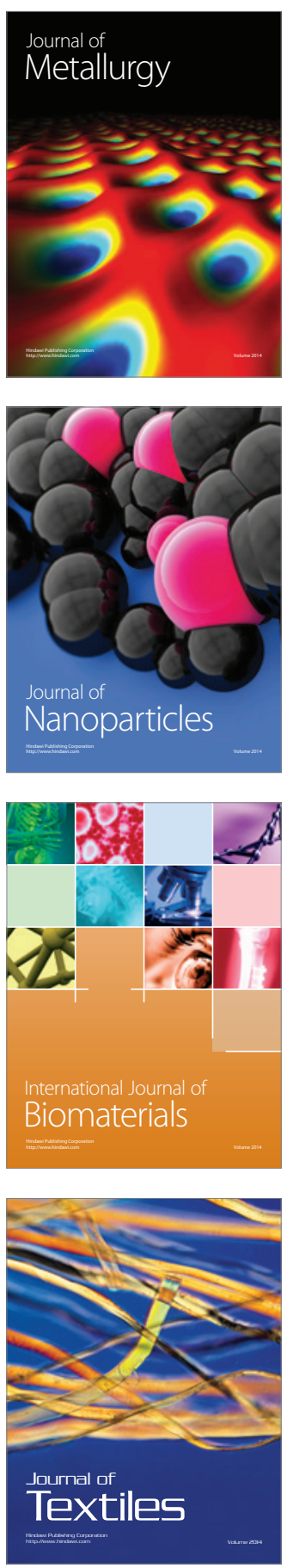